Geographia Meridionalis - Revista Eletrônica do Programa de Pós-Graduação em Geografia da Universidade Federal de Pelotas

http://periodicos.ufpel.edu.br/ojs2/index.php/Geographis/index ISSN 2446-9165

Recebido em:15/10/2018

Revisões Requeridas em: 09/01/2019 Aceito em:20/01/2019

\title{
PAISAGENS AMEAÇADAS DA RESTINGA DA LAGOA DOS PATOS (RS): ECOLOGIA DA PAISAGEM COMO CONTRIBUIÇÃO PARA O ZONEAMENTO ECOLÓGICO ECONÔMICO DO LITORAL MÉDIO
}

\author{
THREATENED LANDSCAPES OF THE RESTINGA DA LAGOA DOS PATOS \\ (RS): LANDSCAPE ECOLOGY AS CONTRIBUTION TO THE ECONOMIC \\ ECOLOGICAL ZONING OF THE MIDDLE COAST
}

\author{
Rafael Martins Pinheiro \\ Universidade Federal do Rio Grande \\ Programa de Pós-graduação em Educação Ambiental \\ gohafa@gmail.com \\ Marcelo Dutra da Silva \\ Universidade Federal do Rio Grande \\ Laboratório de Ecologia da Paisagem Costeira \\ dutradasilva@terra.com.br
}

\section{RESUMO}

A Restinga da Lagoa dos Patos (RLP) compreende São José do Norte, Tavares, Mostardas e Palmares do Sul. O objetivo deste trabalho foi reconhecer as paisagens ameaçadas com base nas formas de uso e ocupação do espaço. Foi utilizado um mapa base de classes de paisagem que correspondem ao uso e ocupação do solo e os descritores métricos foram aplicados aos níveis de classe e da paisagem. As classes antrópicas ocupam mais de dois terços da área total da restinga $(68,6 \%)$. A classe antrópico rural é a matriz da paisagem. São José do Norte está mais susceptível aos impactos ocasionados pelas atividades associadas ao setor do petróleo e gás natural. Tavares, com a presença do Parque Nacional da Lagoa do Peixe (PNLP) possui a maior integridade das áreas naturais. Embora Mostardas abrigue parte do PNLP muitos de seus remanescentes naturais podem ser perdidos devido à expansão do cultivo de soja e da silvicultura. Em Palmares do Sul a expansão dos cultivos de arroz e de soja configuram a principal ameaça. O crescimento econômico sem planejamento territorial é uma ameaça à conservação. Portanto, o zoneamento ecológico econômico costeiro e a criação de unidades de conservação são necessárias ao desenvolvimento sustentável.

Palavras chave: Restinga da Lagoa dos Patos; ecologia de paisagem, métricas. 


\begin{abstract}
The Restinga da Lagoa dos Patos (RLP) includes São José do Norte, Tavares, Mostardas and Palmares do Sul municipalities. The goal of this study was the recognition of the threatened landscapes of the RLP, based on type of use and occupation of space. A base map of landscape's classes was used. The classes correspond to the use and occupation of land. Metrical descriptors were applied to the levels class and landscape. Anthropogenic classes occupy more than twothirds of the total area of RLP (68.6\%). The rural anthropic class is the matrix of the landscape. São José do Norte is more susceptible to the impacts caused by activities from the oil use and gas sector. Tavares, due to the presence of the Parque Nacional da Lagoa do Peixe (PNLP), is the municipality with greater integrity of natural areas. Although Mostardas shelters a part of the PNLP many of its natural remnants may be lost due to agricultural expansion from soybean farming and silviculture. In Palmares do Sul the expansion of rice and soybean plantations figures the major threat. Economic growth without territorial planning threats conservation. Thus, economic ecological zoning and the creation of further environmental protection areas are important actions for sustainable development.
\end{abstract}

Keywords: Restinga da Lagoa dos Patos; landscape ecology; metrics. 


\section{1 - Introdução}

Paisagem é uma área heterogênea da superfície terrestre composta de um conjunto de ecossistemas interativos e que se repetem de forma similar em uma dada extensão de terra (FORMAN \& GODRON, 1986); é um mosaico de terras com formas, tipos de vegetação e uso do solo heterogêneo (URBAN et al., 1987); área espacialmente heterogênea em pelo menos um dos fatores de interesse (TURNER et al., 2001). Uma paisagem organizase como um mosaico de manchas, assim formando um conjunto de ecossistemas que interagem (FORMAN \& GODRON, 1986).

A análise da paisagem pelo ponto de vista da abordagem geográfica envolve o reconhecimento dos elementos da paisagem caracterizados pelos diferentes tipos de uso e cobertura do solo. Ou seja, é aquela porção da paisagem que está na superfície terrestre e pode ser observada como manchas, podendo apresentar diferentes tamanhos, formas, entre outras características. O padrão estrutural de uma paisagem é composto de manchas, corredores e matrizes, sendo esses elementos os instrumentos para a comparação entre diferentes paisagens (FORMAN, 1995).

As manchas são os menores elementos individuais observáveis da paisagem (ZONNEVELD, 1989). É uma das unidades espaciais mais importantes nos estudos da paisagem (FORMAN, 1995) e é definida como uma forma da superfície delimitada não linearmente, de aparência distinta em relação ao entorno (FORMAN \& GODRON, 1986). A análise métrica da paisagem é horizontal e está fundamentalmente integrada a uma base de dados, gerados a partir de imagens de satélite e de programas computacionais (SoaresFilho, 2018). Os descritores métricos são resultado de um processo sistemático de cálculo, constituído por um número determinado de operações que quantificam características específicas aplicadas em nível de manchas, de classes ou de paisagem (MCGARIGAL \& MARKS, 1994).

As métricas de área e de tamanho buscam compreender a estrutura da paisagem, uma vez que quanto maior a mancha natural, maior será a biodiversidades e menor será o efeito de borda. No entanto, manchas pequenas geralmente não possuem manejo adequado e, por consequência, são eliminados da paisagem (METZGER, 1999).

As métricas de borda e de forma são utilizadas principalmente para mensurar a fragmentação, já que o formato de uma mancha tem relação direta com o efeito de borda. 
A borda determina a transição entre o interior de uma mancha com outra mancha ou matriz da paisagem (METZGER \& MULLER,1996).

O índice de forma expressa o quanto a mancha é complexa, medindo o perímetro e área e comparando com formas simples, como um quadrado ou uma circunferência. Este índice é igual a 1 quando todas as manchas são circulares (para polígonos) ou quadrado (para imagem raster) e aumenta com a irregularidade da forma da mancha. As formas circulares são consideradas ideais, isto porque a relação perímetro-área é menor e, com isso, o núcleo da mancha fica protegido dos efeitos da matriz, enquanto que em manchas com formatos mais alongados ou irregulares, o núcleo torna-se desprotegido (MCGARIGAL \& MARKS, 1994).

O índice de diversidade é baseado no componente riqueza, e define a diversidade da paisagem levando em consideração a quantidade de classes representadas e o padrão de distribuição das manchas. O índice será igual a zero se houver apenas uma mancha na paisagem e aumentará à medida que o número de classes aumenta. Já o índice de uniformidade se baseia na componente regularidade, e está relacionado à distribuição e abundância das manchas. O Índice de Uniformidade de Shannon é igual a zero quando a distribuição das manchas observada é baixa, e se aproxima de 1 quando o padrão de distribuição das manchas torna-se mais uniforme. Ele expressa a distribuição das classes na paisagem sem levar em conta a riqueza de classe (MCGARIGAL \& MARKS, 1994). A análise métrica permite reconhecer as relações espaciais entre as diferentes classes e ecossistemas que compõem a paisagem e que podem ser observados e medidos dentro de um conjunto. Isto é, auxilia no reconhecimento do padrão estrutural de uma paisagem, bem como as suas características de composição, fluxos e tendências de mudança. Estudar e compreender as relações inter-horizontais, entre as unidades de espaço de uma paisagem auxilia na caracterização e no diagnóstico territorial. Considerando que estas são premissas para o planejamento e gestão, assim podemos afirmar que a ecologia de paisagem é uma ferramenta importante, contribuindo para o Gerenciamento Costeiro Integrado (GCI).

Segundo a Organização das Nações Unidas (2019), estimam que, no ano 2100, a população mundial alcance aproximadamente 11 bilhões, e provavelmente mais da metade destas pessoas estarão vivendo nas zonas costeiras. É evidente a necessidade do 
GCI, pois estas zonas são de extrema valia devido aos seus diversos serviços ambientais prestados. Já o enfoque integrado é crucial devido aos efeitos que os usos do oceano e do continente podem ocasionar na zona costeira e também um ao outro. Para tanto, é imprescindível uma integração em diferentes níveis de ação, sejam eles governamentais ou sociais (CICCIN-SAIN \& KNECHT, 1998).

O GCI é um conjunto de ações e processos que permite a gestão integrada e participativa dos bens comuns da zona costeira. Esta gestão tem o objetivo de adequar as atividades humanas à capacidade suporte dos ecossistemas, contribuindo com a conservação do ambiente e com a melhoria da qualidade de vida das pessoas. Logo, o GCI deve ser participativo, interativo, adaptativo e contínuo (CICCIN-SAIN \& KNECHT, 1998).

No Brasil 17 estados fazem fronteira com o Oceano Atlântico, quase $8.000 \mathrm{~km}$ de zona costeira que possuem particularidades que envolvem desde formações geológicas e características biológicas distintas, bem como padrões de ocupação humana, diversidade de atividades econômicas e fatores político-sociais que em conjunto representam um grande desafio para o GCI.

Em 1988, o Rio Grande do Sul, por meio da Fundação Estadual de Proteção Ambiental Henrique Luiz Roessler (FEPAM) iniciou o Programa de Gerenciamento Costeiro GERCO/RS utilizando-se de instrumentos de planejamento e gestão, entre eles o Zoneamento Ecológico Econômico Costeiro (ZEEC) o qual é um mapeamento baseado em estudos técnicos, no qual áreas distintas são identificadas com suas potencialidades e fragilidades (FEPAM, 2000). Ele divide-se em quatro etapas: planejamento, diagnóstico (físico-natural; socioeconômico e socioambiental) prognóstico e implementação (ASMUS et. al., 2006). A zona costeira gaúcha é setorizada em quatro setores: Litoral Norte, Litoral Médio Leste, Litoral Médio Oeste e Litoral Sul (Figura 1).

O Zoneamento Ecológico Econômico do Litoral Médio do Rio Grande do Sul, área na qual se encontra a Restinga da Lagoa dos Patos, é um dos 17 subprojetos do projeto chamado RS-Biodiversidade (RS-BIODIVERSIDADE, 2019). A proposta de zoneamento foi apresentada em duas rodadas de oficinas, no município de Mostardas e no município de Tapes, em 2015, uma vez que o ZEEC expressa as diretrizes regionais de uso dos recursos naturais, a aplicação dessas diretrizes em nível municipal deve passar 
por uma interpretação de caráter local. O mapa preliminar do ZEEC é resultado de estudos e de cruzamentos de informações e dados referentes ao litoral médio.

Inserida no segmento mediano da planície costeira gaúcha encontra-se uma faixa de terra que isola a Lagoa dos Patos do Oceano Atlântico, denominada Restinga da Lagoa dos Patos (RLP), sendo uma das maiores restinga do Brasil, compreendendo os municípios de São José do Norte, Tavares, Mostardas (TAGLIANI, 2011), incluindo Palmares do Sul. Ela traz como características marcantes a presença de áreas úmidas, campos, dunas, matas de restingas e lagoas costeiras, como a Lagoa do Peixe.

Figura 1 - Setorização da Zona Costeira Gaúcha e no destaque a localização da região da restinga da Lagoa dos Patos.

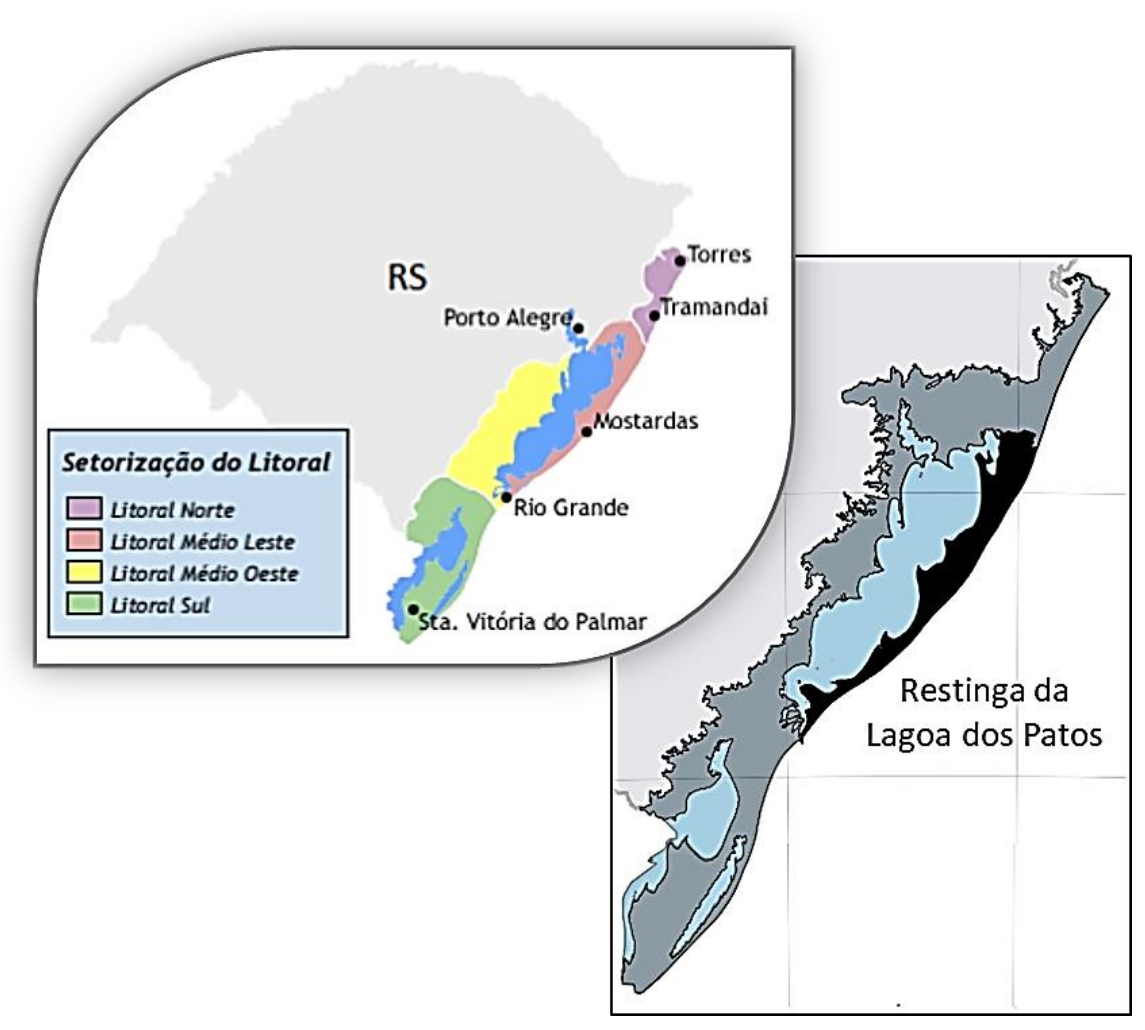

Fonte: Modificado de FEPAM (2016).

Os municípios da RLP desenvolveram a sua economia com base na agricultura, pesca e pecuária. O cultivo de arroz é a principal atividade agrícola em Mostardas e Palmares do Sul, enquanto que em São José do Norte e Tavares destaca-se o cultivo da cebola. Entretanto, diante de períodos de queda na rentabilidade desses cultivos tradicionais outros plantios foram estabelecidos na região. Desde o início desta década, o plantio de 
soja vem ganhando destaque como alternativa, principalmente, em Mostardas e Palmares do Sul (IRGA, 2016). A intensificação da silvicultura foi uma das alternativas encontradas para gerar novos empregos, principalmente em São José do Norte, para aqueles que abandonaram o cultivo da cebola diante de um cenário negativo no mercado (SANTOS, 2007).

Segundo Camargo \& Silva (2002), a RLP está inserida em uma das regiões promissoras para a implantações de usinas eólicas de grande porte. O Parque Eólico de Palmares Sul opera desde 2010 e desde então foram instaladas ao menos sete usinas eólicas. Existem projetos para a instalação de outras usinas nos municípios de São José do Norte e Mostardas (ANEEL, 2017).

Além dessas atividades já consolidadas, outras são pretendidas para a região. A mineração é uma delas. A empresa de capital nacional e com atuação na América latina, Rio Grande Mineração S.A, pretende com o Projeto Retiro a instalação de unidades para a produção de minerais pesados, com destaque para Ilmenita, Rutilo e Zirconita, a partir da exploração (lavra) de depósitos minerais localizados no município de São José do Norte em uma área de aproximadamente 4.900 ha. (RIO GRANDE MINERAÇÃO SA, 2018).

O Estaleiro Brasil - EBR na margem oriental do estuário da Lagoa dos Patos, em São José do Norte, influenciada diretamente pela implantação do Polo Naval de Rio Grande (CABREIRA, 2013) e as possíveis operações de perfuração na Bacia de Pelotas (BP), pode tornar a planície costeira do Rio Grande do Sul uma região estratégica e sob influência dos processos relacionados à indústria do petróleo e gás natural. Além dessa possível exploração de petróleo, há indícios sísmicos de ocorrência de hidratos de gás na região do Cone de Rio Grande, que está localizada na porção sul da Bacia de Pelotas (ANP, 2018).

Embora as pesquisas evidenciam baixo potencial econômico para exploração de petróleo na BP, existe a viabilidade dessa exploração em um futuro próximo, e seriam notáveis os impactos que isto causaria a toda a zona costeira do RS, especialmente para o município de Rio Grande e de São José do Norte, estendendo-se para toda a Restinga da Lagoa dos Patos.

Frente à expectativa de crescimento econômico acredita-se que, à medida que as atividades relacionadas, principalmente, à indústria do petróleo e gás se consolidam, 
ocorra, em paralelo, um maior envolvimento de pessoas que serão atraídas para o processo, elevando as necessidades de novos assentamentos urbanos e a demanda por recursos e alimentos. Logo, tais atividades não trarão apenas mudanças de ordem direta na paisagem, como as resultantes de atividades de instalação e operacionais. Mudanças indiretas, associadas ao crescimento econômico, poderão se manifestar através da multiplicação das formas de uso da terra e do aumento na intensidade dessas atividades.

Com isso, a tendência é que os remanescentes naturais sejam reduzidos, comprometendo a biodiversidade e os serviços prestados pela natureza. O objetivo do presente trabalho é reconhecer as paisagens ameaçadas da RLP, com base nas formas de uso e ocupação e analisar o padrão métrico da paisagem da Restinga e dos municípios de São José do Norte, Tavares, Mostardas e Palmares do Sul.

\section{2 - Metodologia}

O trabalho foi realizado a partir de um mapa de classes de paisagem da planície costeira do Rio Grande do Sul, cedido pelo Laboratório de Ecologia de Paisagem Costeira (LEPCost) da FURG e desenvolvido no trabalho realizado por Lima (2014). As imagens de satélite que originaram o plano temático das classes foram a Landsat 5 sensor TM, do ano de 2011, adquirida na base de imagens do Instituto Nacional de Pesquisas Espaciais (INPE). As dez classes de uso e ocupação do solo que foram adotadas para este estudo são descritas na Tabela 1.

No software Quantum GIS (QGIS 2.12), foi realizado o recorte da área de estudo a partir dos arquivos vetoriais disponibilizados pelo Instituto Brasileiro de Geografia e Estatística (IBGE). Na ferramenta de nós, foram realizados os ajustes entre a base da planície do RS e os arquivos vetoriais do IBGE.

A análise métrica foi realizada no ArcGIS 10.0 com o auxílio do plug-in Patch Analyst 5.1 (REMPEL et al., 1999). Foram utilizados descritores métricos de área; de densidade e tamanho de manchas; de borda e de forma que foram aplicadas aos planos de classe e da paisagem. Os índices de diversidade foram aplicados apenas para o plano da paisagem. 
Tabela 1 - Classes de uso e ocupação do solo consideradas na paisagem.

\begin{tabular}{|c|c|c|}
\hline Nome & Constituição & Tipo \\
\hline Estradas & $\begin{array}{l}\text { Rodovia federal, estradas pavimentadas ou não } \\
\text { pavimentadas. }\end{array}$ & Antrópico \\
\hline Antrópico Urbano & Cidades e ocupações urbanas. & Antrópico \\
\hline Antrópico Rural & $\begin{array}{l}\text { Propriedades rurais de tamanhos variados com } \\
\text { qualquer tipo de atividade agrícola. }\end{array}$ & Antrópico \\
\hline Areias e Dunas & $\begin{array}{l}\text { Dunas sem vegetação, grandes áreas de areia, } \\
\text { como em meandros de rios, deltas e paleodunas. }\end{array}$ & Natural \\
\hline Campo Nativo & $\begin{array}{l}\text { Campos naturais sem presença significativa de } \\
\text { atividade pecuária. }\end{array}$ & Natural \\
\hline Corpos d'água & $\begin{array}{l}\text { Corpos d'agua naturais ou artificiais; rios, } \\
\text { córregos, lagos, e canais de irrigação. Sem a } \\
\text { presença da Lagoa dos Patos. }\end{array}$ & Natural \\
\hline Cultivos Florestais & $\begin{array}{l}\text { Plantações de espécies florestais, basicamente, } \\
\text { Eucaliptos e Pinus. }\end{array}$ & Antrópico \\
\hline Dunas vegetadas & Dunas fixadas por vegetação natural. & Natural \\
\hline Matas Nativas & Matas de Restingas, remanescentes de matas. & Natural \\
\hline Áreas Úmidas & $\begin{array}{l}\text { Campos úmidos encharcados, marismas e } \\
\text { banhados. }\end{array}$ & Natural \\
\hline
\end{tabular}

Fonte: adaptado de Lima (2014).

A análise da paisagem foi realizada para a região da restinga e para os quatro municípios separadamente. Os dados de área plantada com arroz, cebola e soja, para cada município, foram obtidos através do site da Fundação de Economia e Estatística Siegfried Emanuel Heuser (FEE).

\section{3 - Resultados e Discussão}

\section{1 - Análise da Paisagem da Restinga da Lagoa dos Patos}

O tamanho médio das machas da RLP (TMM) é de 55,43 ha ( $\pm 532,16$ ha). Os maiores TMM são das classes antrópico urbano (131,56 ha) seguido da classe Areias e Dunas (118,69 ha) e o menor é das Matas Nativas (9,91 ha). O TMM da paisagem não nos revela o estado ambiental dos ambientes naturais, já que nesta análise estão incluídas as manchas antrópicas que totalizam 317.698,56 ha (68,61 \%), distribuído em 3.636 manchas. A área total das manchas naturais ocupa uma parcela menor da paisagem 145.329, 54 ha $(31,39 \%)$, no entanto representa $56,47 \%$ do total de manchas, sendo assim é mais fragmentada que a área antrópica (Tabela 2). 
Tabela 2 - Descritores métricos da paisagem da Restinga da Lagoa dos Patos.

\begin{tabular}{ccccccccc}
\hline Área & \multicolumn{4}{c}{ Densidade e Tamanho } & & Borda & & Forma \\
\hline AP & NM & DM & TMM & DPTM & TB & TMB & DB & IFP \\
& & & & & & & & \\
\hline ha & ad & $\mathrm{m} / \mathrm{ha}$ & ha & Há & $\mathrm{km}$ & $\mathrm{km} / \mathrm{ma}$ & $\mathrm{m} / \mathrm{ha}$ & $\mathrm{ad}$ \\
& & & & & & & & \\
\hline 463028,10 & 8353 & 1,80 & 55,43 & 532,16 & 27618,05 & 3,31 & 59,65 & 2,01
\end{tabular}

$\overline{\text { AP-área da paisagem; na-área natural; NM-número de manchas; DM-densidade de }}$ manchas; TMM-tamanho médio das manhas; DPTM-desvio padrão do tamanho das manchas; TB-total de bordas; TMB-tamanho médio das bordas; DB-densidade de bordas; IFP-índice de forma da paisagem; IDS-índice de diversidade de Shannon; IUS-índice de uniformidade de Shannon. Fonte: autor.

A classe antrópico rural ocupa 59,36\% da paisagem (Tabela 3). Conforme o critério componente de área, ela pode ser determinada como a matriz da paisagem, pois representa mais de 50\% da área da paisagem (FORMAN \& GODRON, 1986). Atividades associadas a essa classe são o principal fator de fragmentação e supressão dos ecossistemas que compõe a RLP.

O número de manchas da paisagem é proporcional ao valor do total de bordas (TB) $(27.618,05 \mathrm{~km})$. Isto significa que quanto maior for o número de manchas $(\mathrm{NM})$, maior será a heterogeneidade, a fragmentação e o retalhamento da paisagem, sem determinar, entretanto, o estado de conservação ambiental. E quanto menos fragmentada uma paisagem, maior é tamanho médio das bordas das manchas (TMB) $(3,31 \mathrm{~km} / \mathrm{mancha})$. 
Tabela 3 - Descritores métricos de classes da Restinga da Lagoa dos Patos.

\begin{tabular}{|c|c|c|c|c|c|c|c|c|}
\hline \multirow{3}{*}{ Classes } & Área & \multicolumn{3}{|c|}{ Densidade e Tamanho } & \multicolumn{3}{|c|}{ Borda } & \multirow{2}{*}{$\frac{\text { Forma }}{\text { MIF }}$} \\
\hline & $\mathrm{AC}$ & NM & TMM & DPTM & $\mathrm{TB}$ & TMB & DB & \\
\hline & ha & $\overline{A d}$ & ha & ha & $\mathrm{km}$ & $\mathrm{km} / \mathrm{ma}$ & $\mathrm{m} / \mathrm{ha}$ & $\mathrm{ad}$ \\
\hline & 15349 & 57 & 28,96 & $\overline{868}$ & 3377,69 & & 7,29 & 14,42 \\
\hline Antró & 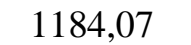 & 9 & & & 5836 & & 0,13 & 1,71 \\
\hline Antró & 274858,25 & 2788 & & & 10056,55 & & 21,72 &, 54 \\
\hline Arei & 51133,07 & 1136 & 45 & & 2351,78 & 2,07 & 5,08 & 1,44 \\
\hline Camp & 84,77 & 133 & 118 & & 893,04 & & 1,93 & 2,03 \\
\hline & 037,44 & 1858 & & & 5410,80 & 2,91 & 11,69 & 3,32 \\
\hline Cultivo & 40121,32 & 782 & 52,03 & 192 & 2490,77 & 3,19 & 5,38 & 1,62 \\
\hline Duna & 15485,34 & 356 & 44,18 & 183,37 & 1128,30 & 3,17 & 2,44 & 1,55 \\
\hline & 4153,70 & 423 & & 27, & 551,05 & 1,30 & 1,19 & 1,46 \\
\hline Áreas úmidas & 16235,22 & 811 & 19,66 & 105,43 & 1299,72 & 1,60 & 2,81 & 1,46 \\
\hline
\end{tabular}

AC-área da classe; NM-número de manchas; TMM-tamanho médio das manhas; DPTMdesvio padrão do tamanho das manchas; TB-total de bordas; TMB-tamanho médio das bordas; DB-densidade de bordas; MIF-média do índice de forma. Fonte: autor.

As manchas naturais que outrora estavam conectadas apresentam-se fragmentadas, sobretudo por manchas agrícolas. Entretanto, as demais classes antrópicas também atuam nos processos de fragmentação e retalhamento. Os cultivos de espécies florestais com 782 manchas e área total de 40.121,32 ha $(8,66 \%)$. As estradas, apesar de apresentarem uma área pequena de $1.534,92$ ha $(0,33 \%)$ e um baixo número de manchas (57) manchas apresentaram o maior TMB entre todas as classes $(59,26)$, devido ao formato linear. A BR 101 é a única rodovia que interliga os municípios da RLP. Devido as suas condições precárias, principalmente antes de ser asfaltada foi denominada como "Estrada do Inferno". Podemos considerá-la uma estrada relativamente estreita, pois possui apenas duas pistas de rolagem, uma em cada sentido, e com pouco tráfego quando comparada a outras rodovias da planície costeira do Rio Grande do Sul.

O índice de forma da paisagem $(2,4)$ possui relação com o formato alongado da Restinga e com as manchas com formatos lineares. A classe estradas foi a que apresentou a forma mais linear $(14,42)$ seguida pela classe corpos d'água $(3,32)$, principalmente devido aos canais de irrigação, que tendem a servir como corredores, filtros ou barreiras ao fluxo, quando dividem o espaço.

As manchas de classes antrópicas apresentam as formas mais complexas, enquanto que as naturais são menos complexas, ou seja, se assemelham a forma circular. Se não levássemos em consideração as manchas de estradas, por exemplo, o índice de forma nos 
daria evidências de uma paisagem menos impactada. No entanto, a classe antrópico rural é a grande responsável pela transformação na paisagem e suas manchas apresentam uma média do índice de forma (MIF) de 1,54, demonstrando um baixo grau de complexidade desta classe.

As manchas naturais irregulares ou as mais complexas estão mais suscetíveis aos efeitos de borda, principalmente as que possuem áreas menores em razão da maior interação com a matriz, a classe antrópico rural. Com o aumento do efeito de borda ocorre a diminuição da área núcleo dessas manchas, e isto irá influenciar na estrutura do ecossistema.

Dentre as classes naturais, destacam-se com as maiores áreas as classes areias e dunas com 51.133,07 ha (11,04\%) e corpos d'água com 43.037,44 ha (9,29\%); as áreas úmidas com $16.253,22$ ha $(3,51 \%)$; as dunas vegetadas com $15.485,34$ ha $(3,34 \%)$; os campos remanescentes $15.284,77$ ha $(3,30 \%)$ e as matas nativas com 4153,70 ha representando a menor área $(0,90 \%)$.

Grandes manchas de areias e dunas ocorrem com mais frequência próximas à linha de costa do oceano Atlântico, e manchas menores próximas à Lagoa dos Patos, associadas às paleodunas. No Rio Grande do Sul, as dunas são áreas de preservação permanente (APP). Sendo assim, para a realização de quaisquer atividades se fazem necessárias autorizações de órgãos ambientais. Entretanto, podemos verificar recentes assentamentos urbanos nestes ambientes ao longo da Restinga, representando juntamente com a expansão das áreas de silvicultura uma ameaça à integridade ambiental.

As manchas de dunas vegetadas, encontradas ao longo de toda a linha de costa do oceano, apresentam uma extensão comparável à classe campos remanescentes. No entanto, o número de manchas de dunas vegetadas é quase três vezes maior (356) que de campos, evidenciando a sua fragmentação. Estas também são APP's devido ao papel que desempenham nos processos morfodinâmicos costeiros.

As 133 manchas de campos remanescentes com TMM de118,69 $( \pm 317,65)$ e TMB de $6,71 \mathrm{~km} / \mathrm{manch}$, são os maiores apresentados entre as classes naturais. O elevado tamanho das manchas desta classe compensa o alto valor da MIF de 2,03, que poderia causar desproteção ao núcleo das manchas caso o TMM fosse menor. A maior mancha desta classe encontra-se no município de Mostardas. A expansão agrícola é a umas das 
principais ameaças a estes ambientes sendo que em outras regiões do Rio Grande do Sul verifica-se o mesmo fenômeno.

As áreas úmidas apresentam uma área total um pouco maior que a das classes campos remanescentes e dunas vegetadas, distribuídas em um número superior de manchas, 811. O TMM das manchas de 19,66 ha $( \pm 105,43)$ é pequeno quando comparado com o tamanho das manchas das outras duas classes já citadas, reflexo da elevada fragmentação desse ambiente. O MIF é 1,46, o que poderá compensar o baixo TMM, no que se refere à proteção do núcleo das manchas. As áreas úmidas compreendem diversos ambientes cobertos por água, temporariamente ou permanentemente, são ecótonos entre ambientes aquáticos (marinhos ou continentais) e terrestres, além de abrigar uma diversidade de espécies.

A classe corpos d'água apresentou o maior número de manchas dentre as classes naturais: 1851 manchas com TMM de 23,49 ( \pm 322,23). O alto valor do DPTM está associado à presença de grandes Lagoas como a Lagoa do Peixe, com maior porção em Tavares e menor em Mostardas; a Lagoa do Capão do F e a Lagoa Reserva em Mostardas; Lagoa da Porteira e Lagoa do Quintão em Palmares do Sul. A densidade de borda (DB) de 11,72 $\mathrm{m} / \mathrm{ha}$ evidencia a grande área da classe, já que a mesma apresenta uma grande quantidade de manchas.

Das 423 manchas de matas nativas algumas são representadas por matas ciliares. A baixa ocorrência desta classe pode ser explicada devido ao fato da região da Restinga ser de formação geológica recente, não apresentando, de um modo geral, solos que deem suporte ao estabelecimento de comunidades vegetais em maiores extensões e densidade. Essas matas ocorrem em pequenas manchas, TMM de 9,91 $( \pm 27,51)$, e não podemos descartar a pressão da expansão agrícola como principal fator associado à fragmentação e supressão desses ambientes. O baixo valor do TMM significa uma menor proteção ao núcleo destes fragmentos. As matas nativas estão dispersas por toda a paisagem da Restinga. Esse tipo de vegetação se desenvolveu sob a proteção de cercas, fator que dificultou a predação por parte do gado. Em certo momento a cerca desapareceu, e favoreceu o fluxo florestal ao longo de toda a região (TAGLIANI, 2011). O alto grau de fragmentação desta classe é comprovado pelo baixo valor de TMB, 1,32 km/mancha. A MIF de 1,46 demonstra que as manchas de matas nativas podem se assemelhar à forma circular, contribuindo para 
reduzir o efeito de borda. $\mathrm{O}$ processo de fragmentação das matas nativas pode ter origem a partir de novas colonizações da vegetação arbórea, ou seja, podem ocorrer avanços de vegetação em formas de capões (nucleação) e não somente fragmentação como resultado das atividades antrópicas.

O espaço da Restinga da Lagoa dos Patos (RLP) encontra-se transformado, principalmente, pelas classes antrópico rural e cultivo de exóticas florestais. Independentemente do tamanho das manchas, a simplificação do espaço ocasionou a reprodução de formas parecidas e com pouca complexidade. O índice de uniformidade de Shannon (IUS) tem influência direta destas classes. Se a classe antrópico rural não fosse a matriz, esta seria uma paisagem mais diversificada com uma maior presença de ambientes naturais mais íntegros. No entanto, os municípios da Restinga dedicam-se às atividades antrópicas (agrícolas e a silvicultura) que dominam a paisagem, tornando-a menos uniforme e com alto valor de dominância.

Para a RLP, o Índice Diversidade de Shannon foi 1,40 e o Índice de Uniformidade de Shannon foi 0,61 . Ou seja, a Restinga é uma paisagem heterogênea, com diversidade de classes e com pouca uniformidade, que é quebrada pela tendência à dominância, imposta pela classe antrópico rural (Figura 2). 
Figura 2 - Mapa de uso e ocupação do solo da Restinga da Lagoa dos Patos

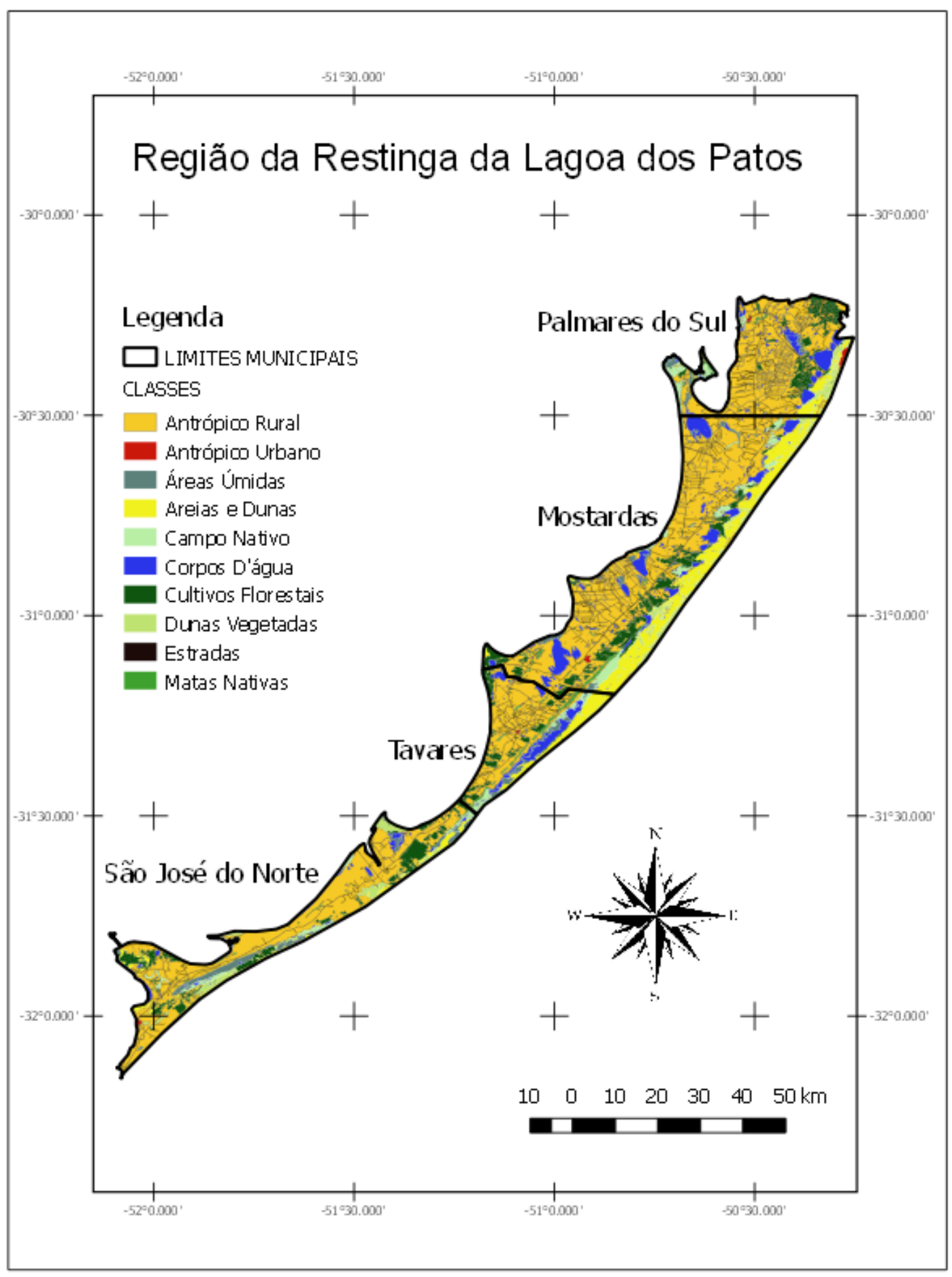

Fonte: autor. 


\section{2 - A Paisagem no Contexto Dos Municípios da RLP}

\section{$\underline{\text { São José do Norte }}$}

É o município (TAP 110.451,71 ha) mais ao sul da Restinga da Lagoa dos Patos, e também o mais povoado (23,2 habitantes/km²) (IBGE, 2016) (Tabela 4). Apresentou 1.776 manchas, as quais 65\% são naturais, revelando uma grande fragmentação da área natural. Devido ao elevado tamanho das manchas antrópicas entre os quatro municípios, é aquele que apresenta a menor densidade de manchas $(1,61)$.

Tabela 4 - Descritores métricos da paisagem de São José do Norte.

\begin{tabular}{ccccccccccc}
\hline Área & \multicolumn{4}{c}{ Densidade e Tamanho } & & Borda & & \multicolumn{2}{c}{ Forma } & \multicolumn{2}{c}{ Diversidade } \\
\hline AP & NM & DM & TMM & DPTM & TB & TMB & DB & IFP & IDS & IUS \\
\hline ha & ad & m/ha & ha & ha & Km & km/ma & $\mathrm{m} / \mathrm{ha}$ & ad & ad & ad \\
\hline 110451,71 & 1776 & 1,61 & 62,19 & 599,12 & 5791,66 & 3,26 & 52,44 & 1,80 & 1,40 & 0,61 \\
\hline
\end{tabular}

Fonte: autor.

Em comparação com os outros municípios, a sua paisagem é a menos complexa (IFP 1,80), embora tenha uma forma alongada, assim como toda a Restinga. Algumas manchas que se assemelham a um círculo, como as de matas nativas, contribuem para a baixa complexidade da paisagem por serem mais regulares, no entanto nem todas as classes naturais apresentam a mesma regularidade.

A matriz antrópico rural com 66.321,93 ha (60,05 \%) distribuída em 458 manchas possui um TMM de 144,81 ha $( \pm 1111,37$ ) (Tabela 5). Segundo dados do IBGE, nos últimos 10 anos, São José do Norte - o maior produtor de cebola do RS - manteve a média de 2.000 ha de área para o cultivo. No entanto, em 1991, o município utilizava uma área de 4.000 hectares, enquanto que no ano de 2014 essa área foi reduzida a 2.000 hectares.

Durante a década de 2004 a 2014, a área plantada não ultrapassou 2.300 hectares ao ano. Comparando apenas os anos de 1991 e 2014, observamos um decréscimo de 55\% na área destinada ao cultivo de cebola no município em questão.

O cultivo de arroz manteve uma média de, aproximadamente, 2.000 ha na última década. Em 1996, mais de 4.500 ha foram destinados ao cultivo do grão, porém no ano seguinte, 1997, observou-se uma significativa redução da área cultivada para aproximadamente 1700 hectares (IBGE, 2016). O milho é a quarta cultura temporária mais importante nos 
municípios da Restinga. No entanto, na última década, São José do Norte apresentou um decréscimo de área plantada. Em 2004 foram 400 ha, enquanto que em 2014 a área foi para 150 ha.

Tabela 5 - Descritores métricos de classes de São José do Norte.

\begin{tabular}{ccccccccc}
\hline \multirow{2}{*}{ Classes } & \multicolumn{9}{c}{ Área } & \multicolumn{3}{c}{ Densidade e Tamanho } & \multicolumn{3}{c}{ Borda } & & Forma \\
\cline { 2 - 10 } & AC & NM & TMM & DPTM & TB & TMB & DB & MIF \\
\cline { 2 - 10 } & Há & ad & ha & ha & km & $\mathrm{km} / \mathrm{ma}$ & $\mathrm{m} / \mathrm{ha}$ & $\mathrm{ad}$ \\
\hline Estradas & 323,25 & 13 & 24,87 & 72,10 & 623,50 & 47,96 & 5,64 & 16,29 \\
Antrópico urbano & 177,25 & 3 & 59,08 & 74,62 & 10,60 & 3,53 & 0,10 & 1,40 \\
Antrópico rural & 66321,93 & 458 & 144,81 & 1111,37 & 1985,84 & 4,34 & 17,98 & 1,49 \\
Areias e dunas & 7295,85 & 464 & 15,72 & 94,37 & 746,47 & 1,61 & 6,76 & 1,47 \\
Campos nativos & 3423,77 & 22 & 155,63 & 269,47 & 221,97 & 10,09 & 2,01 & 2,19 \\
Corpos d'água & 8239,76 & 275 & 29,96 & 369,15 & 812,82 & 2,96 & 7,36 & 2,78 \\
Cultivos florestais & 11531,47 & 153 & 75,37 & 262,25 & 595,60 & 3,89 & 5,39 & 1,62 \\
Dunas vegetadas & 6229,97 & 79 & 78,86 & 267,95 & 325,87 & 4,12 & 2,95 & 1,61 \\
Matas nativas & 539,03 & 162 & 3,33 & 7,79 & 116,09 & 0,72 & 1,05 & 1,33 \\
Áreas úmidas & 6369,44 & 147 & 43,33 & 218,34 & 352,90 & 2,40 & 3,20 & 1,46 \\
\hline
\end{tabular}

Fonte: autor.

Com base nos Censos demográficos do IBGE de 2000 e de 2010, é possível fazer uma comparação entre os percentuais populacionais urbanos e rurais no município. Em 2000, $73 \%$ da população era considerada urbana, enquanto que em 2010 correspondia a $68 \%$. Ou seja, a população rural aumentou $5 \%$ entre um estudo e outro.

Apesar do aumento populacional rural, os dados indicam que a área destinada ao cultivo da cebola diminuiu e a produção se intensificou (IBGE, 2016). Esse incremento de produtividade pode estar relacionado a políticas públicas do Governo Federal aplicadas à agricultura de pequena escala, como o Programa Nacional de Fortalecimento da Agricultura Familiar - Pronaf, que contribuiu para o desenvolvimento do setor, principalmente na região Sul do país. Entretanto, as atividades relacionadas ao Polo Naval de Rio Grande e à instalação do Estaleiro EBR em São José do Norte, atraíram para o município uma quantidade considerável de habitantes (EBR, 2016). Este fato aumentou a demanda por infraestrutura urbana, principalmente nas localidades periféricas ao centro da cidade, o que pode estar contribuindo com o incremento populacional das áreas rurais. 
Com mais de $70 \%$ da área do município destinada às atividades agrícolas e à silvicultura - e estas serem atualmente a base da economia -, São José do Norte não é considerado um município rural, mas em situação de transição entre rural e urbano.

Acredita-se que, à medida que a indústria do petróleo e gás se reestabeleça, essas atividades tragam um novo panorama para o município, trazendo infraestrutura e constituindo uma expansão da zona urbana da cidade, que é concentrada em três áreas (manchas).

A classe cultivo de exóticas florestais tem área de 11.531,47 ha (10,44\%), sendo a maior área desta classe dentre os municípios da Restinga. Isto se deve ao fato de São José do Norte ser o maior representante na produção de madeira em tora e resina. A dispersão descontrolada do pinnus é um dos principais problemas associados a esta atividade, ocasionando danos ambientais.

As grandes parcelas agrícolas e as manchas da classe de cultivo de exóticas florestais contribuem para elevar o TMM da paisagem do município (62,19 ha).

O campo apresenta área de 3.423,77 ha (3,10\%), distribuída em 22 manchas (o menor número de manchas entre as classes naturais do município). Destaca-se, positivamente, o TMM de 155,63 ha, sendo o maior apresentado para a paisagem, superando o da classe antrópico rural, o que pode conferir às manchas uma razoável proteção ao núcleo. As manchas de campos possuem formas mais complexas quando comparadas com as de outras classes naturais, (com exceção dos corpos d'água).

Estes ambientes estão concentrados em grandes áreas e estes ambientes estão relativamente bem conservados.

Os corpos d'água apresentam a maior área total entre as classes naturais, 8.239,76 ha $(7,46 \%)$ distribuídos em 275 manchas. O TMM de 29,96 ha se deve à grande quantidade de manchas. Mesmo apresentando a maior área total entre as classes naturais, o TMB foi de 2,96 km/manchas devido à grande quantidade de manchas. Os maiores corpos d'agua estão concentrados e as manchas de pequenos tamanhos dispersas.

A classe areais e dunas tem uma área total de 7.295,85 ha (6,61\%) distribuída em 464 manchas, apresentando o segundo menor TMM (15,72 ha). Estão distribuídas ao longo da costa oceânica com manchas maiores concentradas ao norte do município e manchas 
menores ao sul. O elevado número de manchas contribuiu para o baixo TMM desta classe, bem como para o baixo valores de TMB $(1,61 \mathrm{~km} /$ mancha) e para o alto valor de densidade de borda (6,76 metros/hectares). São as manchas naturais mais regulares (MIF $1,47)$.

A classe dunas vegetadas tem uma área total de 6.369,44 ha (5,64\%) distribuída em 79 manchas, e o segundo maior TMM de 78,86 ha, entre as classes naturais. Estão dispersas ao longo da linha de costa. Tavares é o único que apresenta dunas vegetadas junto à Lagoa dos Patos. Estas manchas apresentam formas mais simples quando comparado com as outras manchas naturais

As áreas úmidas com área de 6.369,44 ha (5,77 \%) com 147 manchas de TMM de 43,33 ha. Concentram-se basicamente em quatro grandes áreas e são ameaçadas pela silvicultura. O conjunto de métricas indicam que, apesar de ocuparem uma área significativa na paisagem do município, encontram-se fragmentadas, ainda que, dentre os quatro municípios, tenham apresentando o maior TMM para a classe.

A classe matas nativas representam uma área de apenas 539,03 ha (0,49\%). O elevado número de manchas desta classe (163 manchas) com um TMB de $0,72 \mathrm{~km} /$ mancha e uma DB de 1,05 m/ha constata que estes ambientes necessitam de grandes esforços de conservação devido ao seu alto grau de fragmentação, ao reduzido tamanho de suas manchas e da pequena área total da classe. O MIF desta classe foi o menor 1,33 ( $\pm 1,92)$, ou seja, as manchas desta classe estão mais semelhantes a um círculo (quando comparadas às manchas de outras classes). Apesar de apresentar índice de forma satisfatório do ponto de vista da conservação, os outros descritores métricos evidenciam que, dos quatro municípios, as matas nativas de São José do Norte apresentam o pior estado de conservação. O TMM de 3,33 ha foi o menor valor, corroborando com a hipótese de que estes ecossistemas estão seriamente ameaçados.

\section{$\underline{\text { Tavares }}$}

É o município com o menor número de manchas (1.039 manchas), sendo também o menor em área dentre os quatro municípios (60.748,33 ha), com densidade demográfica de 8,9 hab/ km² (IBGE, 2016) (Tabela 6). O município apresenta o maior percentual de área natural (37\%), devido ao fato de estar inserida em seu território a maior porção de área do Parque Nacional da Lagoa do Peixe (PNLP). O TMM da paisagem foi de 58,47 ha. 
Tabela 6 - Descritores métricos da paisagem de Tavares.

\begin{tabular}{ccccccccccc}
\hline Área & \multicolumn{4}{c}{ Densidade e Tamanho } & \multicolumn{3}{c}{ Borda e Forma } & \multicolumn{3}{c}{ Diversidade } \\
\hline TAP & NM & DM & TMM & DPTM & TB & TMB & DB & IFP & IDS & IUS \\
\hline ha & ad & m/há & ha & Ha & $\mathrm{km}$ & $\mathrm{km} / \mathrm{ma}$ & $\mathrm{m} / \mathrm{ha}$ & $\mathrm{ad}$ & $\mathrm{ad}$ & $\mathrm{ad}$ \\
\hline 60748,33 & 1039 & 1,71 & 58,47 & 393,27 & 3573,34 & 3,44 & 58,82 & 2,07 & 1,49 & 0,65 \\
\hline
\end{tabular}

A classe antrópico rural apresenta uma área de 33204,11 ha distribuída em 224 manchas de TMM 148,23 ha (Tabela 7). A cebola e o arroz são os cultivos temporários mais influentes na economia do município. Na última década, pôde-se observar um aumento da área destinada ao cultivo de cebola. Em 2004, foram utilizados 600 ha, enquanto que em 2014 a área aumentou para 1.100 ha. Em 1994, o município destinava 2.500 hectares de área às plantações do bulbo e, após uma década, houve uma acentuada redução do cultivo (IBGE, 2016). Ao cultivo de arroz foram destinados, no ano de 2004, 2.864 ha, sendo que, dois anos depois, a área plantada foi reduzida a 1.511 ha. O cultivo de milho em Tavares também apresentou um decréscimo, de 650 ha em 2004, para aproximadamente 200 ha em 2014.

Tabela 7 - Descritores métricos de classes de Tavares.

\begin{tabular}{|c|c|c|c|c|c|c|c|c|}
\hline \multirow{3}{*}{ Classes } & \multirow{2}{*}{$\begin{array}{c}\text { Área } \\
\text { AC }\end{array}$} & \multicolumn{3}{|c|}{ Densidade e Tamanho } & \multicolumn{3}{|c|}{ Borda } & \multirow{2}{*}{$\begin{array}{c}\text { Forma } \\
\text { MIF }\end{array}$} \\
\hline & & NM & TMM & DPTM & $\mathrm{TB}$ & TMB & $\mathrm{DB}$ & \\
\hline & Há & $\mathrm{ad}$ & ha & ha & $\mathrm{km}$ & $\mathrm{km} / \mathrm{ma}$ & $\mathrm{m} / \mathrm{ha}$ & $\mathrm{ad}$ \\
\hline Estradas & 222,65 & 10 & 22,27 & 63,75 & 481,68 & 48,17 & 7,93 & 14,69 \\
\hline Antrópico urbano & 103,56 & 1 & 103,56 & 0 & 8,37 & 8,37 & 0,14 & 2,32 \\
\hline Antrópico rural & 33204,11 & 224 & 148,23 & 611,58 & 1194,98 & 5,33 & 19,67 & 1,58 \\
\hline Areias e dunas & 7301,67 & 138 & 52,91 & 571,95 & 278,73 & 2,02 & 4,59 & 1,49 \\
\hline Campos nativos & 2473,99 & 8 & 309,25 & 512,49 & 157,19 & 19,65 & 2,59 & 2,53 \\
\hline Corpos d'água & 7169,17 & 223 & 32,15 & 330,56 & 605,22 & 2,71 & 9,96 & 3,52 \\
\hline Cultivos florestais & 4747,48 & 136 & 34,91 & 93,44 & 324,23 & 2,38 & 5,34 & 1,55 \\
\hline Dunas vegetadas & 300,20 & 28 & 10,72 & 15,53 & 40,15 & 1,43 & 0,66 & 1,41 \\
\hline Matas nativas & 1578,04 & 121 & 13,04 & 25,88 & 182,99 & 1,51 & 3,01 & 1,42 \\
\hline Áreas úmidas & 3647,46 & 150 & 24,32 & 79,18 & 299,78 & 2 & 4,93 & 1,45 \\
\hline
\end{tabular}

Fonte: autor.

Em 2007, ocorreu o ápice da redução, com apenas 100 ha. O município de Tavares recentemente foi classificado como em transição entre urbano e rural, pois apresentou no censo de $201062 \%$ dos habitantes residindo na área urbana, que corresponde a uma única 
mancha de 103 ha. No censo de 2000, a população urbana representava $49 \%$ da população de Tavares e o município era considerado rural.

No que se refere às classes naturais, areais e dunas apresentou a maior área, 7.301,67 ha (12,02\%), distribuída em 138 manchas. O TMM das manchas foi de 52,91 ha, o segundo maior TMM das classes naturais. As áreas naturais são rodeadas por áreas destinadas à silvicultura. A falta de um plano de manejo adequado da atividade, inclusive em áreas do PNLP, é uma importante fonte de impacto a estes ecossistemas.

A classe dunas vegetadas apresentou a menor área entre todas as classes da paisagem com apenas 300,20 ha distribuídos em apenas 28 manchas. O TMM também é o menor (10,72 ha). O TMB foi o menor entre as classes naturais (1,43km/manchas). Esses fragmentos encontram-se em situação desfavorável quanto à conservação, pois o tamanho das manchas é pequeno, no entanto sua qualidade funcional é extremamente significativa. A MIF 1,41 teve o menor valor entre as classes naturais, o que se configuraria em algo positivo caso as não fosse tão pequenas.

A classe corpos d'água, com uma área de 7.169,17 ha, representa 11,80\% da paisagem total do município, distribuída em 223 manchas, o maior número de manchas entre as classes naturais, com TMM de 32,15 ha. Tavares apresentou uma área bastante significativa de corpos d'água, tendo em vista que é o menor dos quatro municípios, devido à presença da Lagoa do Peixe.

As áreas úmidas apresentam área de 3.647,46 ha (6\%), distribuída em 150 manchas com TMM de 24,32 ha. Em relação aos demais municípios estes ambientes apresentam-se em considerável estado de conservação, uma vez que em relação à sua área total, Tavares é o município com a maior área de ambientes úmidos. São manchas grandes, contínuas e concentradas ao redor da Lagoa do Peixe, portanto protegidas pela legislação. Isto favorece o fato de encontrar-se em bom estado de conservação em relação aos demais municípios.

Os campos remanescentes apresentaram uma área de 2.473,99 ha (4,07\%, sendo o maior percentual de área de todos os municípios), distribuída em apenas oito manchas com TMM de 309,25 ha e o TMB foi de 19,65 km/manchas. Estes valores, TMM e TMB, foram os maiores apresentados entre todas as classes naturais dos quatro municípios, o que é positivo do ponto de vista da conservação. A MIF de 2,53, apesar de alto (indicando 
certa complexidade das manchas), não compromete a integridade dos ambientes, devido ao grande TMM. As manchas grandes que se concentram em duas áreas: ao sul da Lagoa do Peixe e ao norte do município. Do ponto de vista da análise espacial, os campos de Tavares estão em bom estado de conservação.

As matas nativas apresentaram área total de 1.578,04 ha (2,60\% da paisagem de Tavares) distribuída em 121 manchas, com TMM de 13,04 ha. As manchas se concentram em um cordão paralelo à linha de costa podendo formar um corredor ecológico na margem oeste da Lagoa do Peixe associada a uma matriz de classe antrópico rural. São maiores na porção Norte do Parque próximo a Mostardas. Tavares concentra 38\% do total da área desta classe na Restinga, apresentando maior tamanho e com índices métricos mais favoráveis quando comparado com os demais municípios.

O índice de uniformidade de Shannon (IUS) de 0,65 foi o maior dentre todos os municípios, superando o valor observado para a Restinga $(0,61)$, consequência do município apresentar significativas parcelas de áreas naturais.

As manchas naturais de Tavares se distribuem em um padrão paralelo à costa. O PNLP é um instrumento eficaz de preservação e, com o manejo e a gestão adequada, podem garantir o equilíbrio dos ecossistemas e manutenção da biodiversidade.

\section{Mostardas}

O maior município da Restinga (197.480,76 ha) e o menos densamente povoado $(6,2$ hab/km²), apresenta o maior número de manchas (3.309). 69\% de suas manchas são naturais, com ênfase para a classe de corpos d'água, com elevado número de manchas (1.003) quando a comparamos entre municípios (Tabela 8). 
Tabela 8 - Descritores métricos da paisagem de Mostardas.

\begin{tabular}{|c|c|c|c|c|c|c|c|c|c|}
\hline \multirow{2}{*}{$\frac{\text { Área }}{\text { AP }}$} & \multicolumn{3}{|c|}{ Densidade e Tamanho } & \multicolumn{3}{|c|}{ Borda } & Forma & \multicolumn{2}{|c|}{ Diversidade } \\
\hline & NM DM & TMM & DPTM & $\mathrm{TB}$ & TMB & $\mathrm{DB}$ & IFP & IDS & IUS \\
\hline ha & $\mathrm{m} / \mathrm{ha}$ & $\mathrm{Ha}$ & $\mathrm{Ha}$ & $\mathrm{Km}$ & $\mathrm{km} / \mathrm{ma}$ & $\mathrm{m} / \mathrm{ha}$ & $\overline{\mathrm{ad}}$ & $\overline{\mathrm{ad}}$ & $\overline{\mathrm{ad}}$ \\
\hline 197480,76 & $3309 \quad 1,68$ & 59,68 & 568,19 & 11095,09 & 3,35 & 56,18 & 2,08 & 1,38 & 0,60 \\
\hline
\end{tabular}

O município apresenta 114.123,72 ha da classe antrópico rural (57,79 \%), distribuídas em 1142 manchas com TMM 99,93 ha (Tabela 9). O plantio de arroz, a principal cultura temporária do município, vem se expandindo nos últimos 25 anos. Observa-se um acréscimo de área plantada onde, em 1991 eram 23.850 ha, e em 2014 aproximadamente 38.000 ha. Na última década, a área plantada manteve uma média de aproximadamente 36.000 ha. O cultivo de cebola é pouco significativo, principalmente quando comparado a São José do Norte e Tavares.

Nos últimos 10 anos, apresentou uma média de 212 ha, com um pico em 2011 de 400 ha e uma redução significativa em 2014 para apenas 90 ha. A área de milho plantada em Mostardas manteve uma média de aproximadamente 500 ha durante a última década, com uma pequena redução em 2012. Em 2014, reaparece uma área bastante expressiva de cultivo de soja. Mostardas, por exemplo, apresentou uma área plantada de 5.000 ha do grão. Nos anos de 2004 e 2005, este cultivo apresentava uma área de apenas 90 ha, sendo que, a partir de 2005, não houve cultivo, ressurgindo em 2014. O município também é classificado como em transição entre urbano e rural. $67 \%$ da população reside na zona urbana municipal que é representada por uma única mancha de 222,2 ha $(0,11 \%)$.

Tabela 9 - Descritores métricos de classes de Mostardas.

\begin{tabular}{ccccccccc}
\hline & Área & \multicolumn{3}{c}{ Densidade e Borda } & \multicolumn{5}{c}{ Borda e Forma } \\
\cline { 2 - 9 } Classes & AC & NM & TMM & DPTM & TB & TMB & DB & MIF \\
\cline { 2 - 10 } & Ha & Ad & Há & ha & Km & km/ma & m/ha & ad \\
\hline Estradas & 577,78 & 13 & 44,44 & 144,62 & 1286,54 & 98,96 & 6,51 & 21,21 \\
Antrópico urbano & 222,20 & 1 & 222,20 & 0,00 & 6,83 & 6,83 & 0,03 & 1,29 \\
Antrópico rural & 114123,72 & 1142 & 99,93 & 755,72 & 4137,79 & 3,62 & 20,95 & 1,58 \\
Areias e dunas & 31520,88 & 330 & 95,52 & 1043,76 & 1054,78 & 3,20 & 5,34 & 1,43 \\
Campos nativos & 6194,64 & 59 & 104,99 & 287,23 & 330,56 & 5,60 & 1,67 & 1,90 \\
Corpos d'água & 18551,97 & 1003 & 18,50 & 168,64 & 2282,11 & 2,28 & 11,56 & 3,01 \\
Cultivos florestais & 15511,99 & 189 & 82,07 & 277,24 & 886,22 & 4,69 & 4,49 & 1,78 \\
Dunas vegetadas & 5994,69 & 210 & 28,55 & 107,49 & 561,12 & 2,67 & 2,84 & 1,49 \\
Matas nativas & 1284,73 & 75 & 17,13 & 50,12 & 147,97 & 1,97 & 0,75 & 1,61 \\
Áreas úmidas & 3498,17 & 287 & 12,19 & 43,27 & 401,18 & 1,40 & 2,03 & 1,50 \\
\hline
\end{tabular}

Fonte: autor. 
A classe areias e dunas apresentou a maior área entre as classes naturais, 31.520,88 ha (15,96\%), distribuída em 330 manchas. A MIF foi a menor entre as classes naturais $(1,43)$. Com base na área da classe e no TMM (95,53 ha) associados à regularidade de forma das manchas, esses ambientes encontram-se num bom nível de conservação.

A classe dunas vegetadas apresentou uma área total de 5.994,69 ha (3,04\%) distribuída em 210 manchas de TMM de 28,55 ha. São manchas associadas às areais e dunas ao longo da linha de costa do oceano. O estado de conservação destes ambientes é melhor do que nos outros municípios. No entanto, é necessário um estado de atenção, tendo em vista que são manchas com tamanho médio não muito elevado e fragmentadas.

A classe corpos d'água, apesar de apresentar um grande número de manchas, não apresentou uma área total de classe maior que das areias e dunas. A sua área representa 9,39\% da paisagem com 1003 manchas e com TMM de 18,50 ha. Mostardas apresenta a maior área total de corpos d'água (18.551,97 hectares) dentre os quatro municípios.

A classe campos remanescentes tem uma área de 6.194 ha $(3,14 \%)$ distribuída em 59 manchas (menor número de manchas entres as classes naturais), com o maior TMM (104,99 ha) bem como o maior TMB (5,60 km/manchas), resultados influenciados pela fragmentação desses ambientes. A maior mancha encontra-se dentro dos limites do PNLP. As outras manchas distribuídas pelo município estão ameaçadas pela expansão dos cultivos agrícolas.

A classe áreas úmidas apresentou uma área de 3.498,17 ha (1,77\% da paisagem) distribuída em 287 manchas de TMM de 12,19 ha. Os descritores métricos indicam o estado de mau conservação desses ambientes. A MIF de 1,50 indica que as manchas, de um modo geral, são de formas pouco complexas. São manchas muito pequenas e dispersas, associadas às lagoas. Esses ambientes necessitam de esforços de conservação. A classe matas nativas apresentou uma área de $1.284,73$ ha $(0,65 \%$ da paisagem $)$ distribuída em 75 manchas de TMM de 17,13 ha. Apesar da MIF de 1,61 indicar um baixo nível de complexidade da forma das manchas. São de tamanho pequeno. As maiores estão dentro dos limites do PNLP. Os fragmentos próximos à costa da Lagoa dos Patos, ao sul do município, e outras pequenas manchas estão ameaçadas, principalmente pelas atividades agrícolas e pela silvicultura. 
Mostardas apresenta uma paisagem heterogênea, com pouca uniformidade, que é quebrada pela tendência à dominância imposta pela classe antrópico rural que apresenta $57,79 \%$ e pela classe areais e dunas com $15,96 \%$. O índice de diversidade de Shannon (IDS) $(1,38)$ e o índice de uniformidade de Shannon (IUS) $(0,6)$ são muito próximos aos valores observados para a Restinga.

\section{Palmares do Sul}

O município tem $94.347,29$ ha e é o segundo mais povoado $\left(11,07 \mathrm{hab} / \mathrm{km}^{2}\right)$, apresentando 2.229 manchas com TMM de 42,33 ha. Possui uma malha mais fina, composta por um número maior de manchas quando comparado aos outros municípios, exibindo a maior densidade de manchas (2,36 mancha/100 ha) (Tabela 10). No entanto, trata-se de manchas, em sua maioria, da classe antrópico rural. Apenas $24 \%$ das manchas são naturais (534), tendo a menor área total natural 23.586,82 ha (25\%). A atividade antrópica nessa porção da paisagem costeira é intensa e distribuída em um grande número de manchas de pequeno tamanho. A paisagem apresenta uma DB elevada $(78,79 \mathrm{~m} / \mathrm{ha})$, o que evidencia a fragmentação dos ambientes.

Tabela 10 - Descritores métricos da paisagem de Palmares do Sul.

\begin{tabular}{ccccccccccc}
\hline Área & \multicolumn{3}{c}{ Densidade e Tamanho } & \multicolumn{3}{c}{ Borda } & \multicolumn{3}{c}{ Forma } & \multicolumn{2}{c}{ Diversidade } \\
\hline TAP & NM & DM & TMM & DPTM & TB & TMB & DB & IFP & IDS & IUS \\
\hline ha & ad & m/ha & ha & ha & Km & $\mathrm{km} / \mathrm{ma}$ & m/ha & ad & ad & ad \\
\hline 94347,29 & 2229 & 2,36 & 42,33 & 234,82 & 7433,99 & 3,34 & 78,79 & 2,15 & 1,30 & 0,56 \\
\hline
\end{tabular}

Fonte: autor.

A classe antrópico rural (64,88\% da área em 964 manchas com TMM de 63,49 ha) e a classe de cultivos de exóticas florestais (8,83\% da área 304 manchas com TMM de 27,4 ha) juntas representam $73,71 \%$ da paisagem e são as grandes responsáveis pela supressão das áreas naturais (Tabela 11).

Dentre os cultivos temporários de Palmares do Sul, destaca-se o de arroz, como o de maior influência na economia local. Na última década, esse cultivo apresentou uma média de 21.000 ha plantados. Ocorreu uma redução na área plantada de arroz entre 1996 e 1997, de 24.500 ha para 14.280 ha, correspondendo ao mesmo período em que houve redução da área em São José do Norte (IBGE, 2016). A produção de cebola em Palmares é inexpressiva, e houve uma pequena expansão nas aéreas destinadas ao cultivo de milho nos últimos dez anos onde, em 2004 eram 400 ha de plantio, e 2014500 ha. Assim como 
em Mostardas, neste município a soja reapareceu de forma expressiva após um longo tempo sem o plantio. Em 2012, havia apenas 60 ha plantados com soja. Em 2014, foram 1100 ha destinados ao cultivo. É importante salientar que, tanto em Palmares do Sul como em Mostradas, não ocorria o plantio do grão de forma tão expressiva pelo menos desde 1991.

Tabela 11 - Descritores métricos de classes de Palmares do Sul.

\begin{tabular}{ccccccccc}
\hline \multirow{2}{*}{ Classes } & \multicolumn{9}{c}{ Área } & \multicolumn{6}{c}{ Densidade e Tamanho } & \multicolumn{3}{c}{ Borda } & Forma \\
\cline { 2 - 10 } & AC & NM & TMM & DPTM & TB & TMB & DB & MIF \\
\cline { 2 - 10 } & ha & ad & ha & ha & km & $\mathrm{km} / \mathrm{ma}$ & $\mathrm{m} / \mathrm{ha}$ & ad \\
\hline Estradas & 411,23 & 21 & 19,58 & 72,57 & 990,22 & 47,15 & 10,50 & 17,08 \\
Antrópico urbano & 681,07 & 4 & 170,27 & 218,17 & 32,56 & 8,14 & 0,35 & 1,89 \\
Antrópico rural & 61208,49 & 964 & 63,49 & 312,42 & 2827,31 & 2,93 & 29,97 & 1,51 \\
Dunas e areias & 5014,68 & 204 & 24,58 & 195,67 & 338,15 & 1,66 & 3,58 & 1,42 \\
Campos nativos & 3192,37 & 44 & 72,55 & 215,68 & 199,76 & 4,54 & 2,12 & 2,05 \\
Corpos d'água & 9076,54 & 357 & 25,42 & 183,01 & 1732,47 & 4,85 & 18,36 & 4,53 \\
Cultivos florestais & 8330,38 & 304 & 27,40 & 74,48 & 702,77 & 2,31 & 7,45 & 1,57 \\
Dunas vegetadas & 2960,49 & 39 & 75,91 & 293,08 & 217,45 & 5,58 & 2,30 & 1,84 \\
Matas nativas & 751,89 & 65 & 11,57 & 19,74 & 106,55 & 1,64 & 1,13 & 1,67 \\
Áreas úmidas & 2720,15 & 227 & 11,98 & 48,94 & 286,75 & 1,26 & 3,04 & 1,42 \\
\hline
\end{tabular}

Fonte: autor.

Dentre os municípios da Restinga, Palmares tem a distribuição populacional mais semelhante à do estado Rio Grande do Sul, que $85 \%$ da população urbana. Portanto, na Restinga, é o mais urbano, com $89 \%$ de sua população residindo nas zonas urbanas do município. As áreas urbanas de Palmares estão concentradas em quatro manchas que somam 681,07 ha (IBGE, 2016). A densidade de bordas $(78,79 \mathrm{~m} / \mathrm{ha})$ foi a maior entre os quatro municípios, consequência de uma paisagem muito fragmentada. O IFP de 2,15 foi o maior dos municípios estudados, as manchas neste município possuem as formas mais complexas. Também foi observado o menor valor para o índice de diversidade de Shannon $(1,30)$.

Das classes naturais, a que apresentou o maior número de manchas e a maior área total foram os corpos d'água (9076,5 ha e 357 manchas), ocupando 9,6\% da paisagem. $O$ tamanho médio dessas manchas é 25,4 ha. A MIF de 4,53 é o maior entre os municípios e também maior que o valor apresentando para a classe quando analisada a Restinga. Esse resultado é influenciado, sobretudo, pela ocorrência de canais de irrigação de lavouras de arroz. 
Areias e dunas é a segunda maior classe natural, ocupando 5,3\% da paisagem do município (5.014,7 ha), com 204 manchas e TMM de 24,6 ha, enquanto as dunas vegetadas representam $3,1 \%$ (2.960,5 ha) e 39 manchas distribuídas ao longo da faixa próxima do oceano, com tamanho médio de 75,9 ha. O assentamento urbano da Praia do Quintão na costa do oceano foi responsável por suprimir uma grande área de ambientes de areais e dunas e de dunas vegetadas. Logo, fazem-se necessárias ações que mantenham a integridade desses ambientes que já sofrem impactos dos processos de urbanização.

Os campos remanescentes com área total de 3.192,4 ha $(3,4 \%)$ distribuídos em 44 manchas de TMM 72,5 ha. Esses fragmentos de campos concentram-se somente junto à linha de costa da Lagoa dos Patos e não seguem a tendência dos outros municípios em ocorrer associados aos ambientes de dunas costeiras. Portanto, acredita-se que, no município estes possam ter sido suprimidos pelas atividades agrícolas e pela silvicultura. Os remanescentes estão ameaçados pela expansão da atividade agrícola.

As áreas úmidas totalizam 2.720,1 ha (2,9\%) distribuídos em 227 manchas com TMM de 12 ha. As maiores manchas se encontram muito próximas das manchas de campos remanescentes, próximo à costa da Lagoa dos Patos.

As matas nativas representam apenas $0,80 \%$ da paisagem (751,9 ha) em 65 manchas de 11,57 ha de tamanho em média. A classe apresenta o menor valor para o parâmetro DB entre as classes naturais (1,13 m/ha). Apesar de apresentar um MIF de 1,67, as manchas desta classe necessitam de esforços de conservação. Concentram-se próximas à sede do município. As maiores manchas são de mata ciliar do Arroio Palmares que é retalhada pela BR-101. As matas nativas de Palmares do Sul, assim como em toda a Restinga, são manchas bastante dispersas e com tamanho pequeno. Logo estão ameaçadas, mesmo aquelas manchas que são protegidas por lei.

Dentre os quatro municípios, Palmares do Sul apresentou os piores resultados para o IDS $(1,30)$ e para o IUS $(0,56)$. A paisagem do município é a menos uniforme, com dominância imposta pelas classes antrópicas, cultivo de exóticas $(8,83 \%)$ e, principalmente, antrópico rural $(64,88 \%)$. 


\section{4 - Conclusões}

Ainda que a Restinga da Lagoa dos Patos abrigue áreas representativas de remanescentes naturais, alguns ecossistemas apresentam-se mais ameaçados do que outros. Em parte devido às características intrínsecas as diferentes formações que compõe o mosaico de ambientes típico de restingas litorâneas, bem como pelas características de uma cobertura vegetal tipicamente pioneira e adaptada às condições extremas locais compondo um mosaico com expressões de fragilidade diferenciadas (alguns ambientes são mais frágeis do que outros).

É importante apresentar a análise métrica e a da paisagem em nível municipal uma vez que estas informações podem contribuir diretamente para o Plano Municipal de Gerenciamento Costeiro - PMGC. São José do Norte está mais susceptível aos impactos ocasionados pelas atividades associadas ao setor do petróleo e gás natural. A ocupação desordenada, a silvicultura e as possíveis atividades de mineração e perfuração da Bacia de Pelotas também ameaçam às áreas naturais.

Devido as características da paisagem e presença do Parque Nacional da Lagoa do Peixe Tavares é o município com maior integridade das áreas naturais. Sendo assim, devidos as restrições determinadas pelo PNLP, o ecoturismo (juntamente com monitoramento ambiental) deve ser incentivado de forma que se torne ainda mais expressivo para a economia local.

Embora Mostardas abrigue parte do PNLP muitos de seus remanescentes naturais podem ser perdidos devido à expansão agrícola, principalmente do cultivo de soja e também da silvicultura.

Devido à distância, o município de Palmares do Sul a expansão dos cultivos de arroz e soja configura a principal ameaça às áreas naturais do município.

O Zoneamento Ecológico Econômico - ZEE é um instrumento necessário à gestão dos ambientes costeiros, pois seus resultados contribuem com as ações que visam à proteção dos recursos naturais e ao desenvolvimento sustentável regional. A utilização de métricas e dos fundamentos da ecologia de paisagem podem auxiliar no processo de elaboração do ZEE uma vez que espacializa informações sobre o estado de conservação das áreas naturais e evidencia os principais impactos e ameaças aos quais esses fragmentos estão submetidos. 


\section{Agradecimentos}

Ao Programa de Recursos Humanos da Agência Nacional do Petróleo, Gás Natural e Biocombustíveis - PRH/27 ANP pela bolsa concedida durante o desenvolvimento do mestrado que deu origem aos dados deste trabalho e ao Laboratório de Ecologia de Paisagem Costeira da Universidade Federal do Rio Grande.

\section{REFERÊNCIAS}

ANEEL - Agência Nacional de Energia Elétrica. Disponível em: <http://www.aneel.gov.br>. Acesso em: 02 de março de 2017.

ANP - Agência Nacional do Petróleo Gás e Biocombustível. Rodadas de Licitações de Petróleo e Gás Natural. Disponível em: <http://rodadas.anp.gov.br/pt/>. Acesso em: 29 de setembro de 2018.

ASMUS, M. L., KITZMANN, D., LAYDNER, C., TAGLIANI, C. R. A. Gestão costeira no Brasil: instrumentos, fragilidades e potencialidades. Gerenciamento Costeiro Integrado, Rio Grande, v. 4, p. 52-57, 2006.

CABREIRA, M. N. Potenciais Impactos na Ocupação da Área Portuária Organizada no Município de São José do Norte RS. 2013. 97 f. Dissertação. (Mestrado do em Gerenciamento Costeiro). Instituto de Oceanografia, Universidade Federal do Rio Grande. Rio Grande. 2013.

CAMARGO, O. A., SILVA, F. J. Atlas eólico: Rio Grande do Sul. Porto Alegre. SEMC - Secretaria de Energia Minas e Comunicações, 2002. 70 p.

CICIN-SAIN, B., KNECHT, R. W. Integrated Coastal and Ocean Management: Concepts and Practices. Washington. Island Press, 1998. 543 p.

EBR - Estaleiro EBR. Estaleiros do Brasil. Disponível em: 〈http://www.ebrbrasil.com/〉. Acesso em: 15 de fevereiro de 2016.

FEPAM - Fundação Estadual de Proteção Ambiental Henrique Luiz Roessler. Diretrizes ambientais para o desenvolvimento do Litoral Norte. Porto Alegre. FEPAM, 2000. Vol. 1. $96 \mathrm{p}$.

FORMAN, R. T. T., GODRON, M. Landscape Ecology. New York. John Wiley \& Sons, 1986. $619 \mathrm{p}$.

FORMAN, R. T. T. Land mosaics: the ecology of landscapes and regions. Cambridge. Cambridge University Press, 1995. 665 p. 
IBGE - Instituto Brasileiro de Geografia e Estatística. Disponível em: <www.fee.rs.gov.br>. Acesso em: 15 de fevereiro de 2016.

IRGA - Instituto Rio Grandense do Arroz. Disponível em: 〈http://www.irga.rs.gov.br>. Acesso em: 01 de outubro de 2016.

LIMA, L. T. A paisagem costeira do Rio Grande do Sul: leitura e interpretação das propriedades fisionômicas do espaço como estratégia de planejamento e gestão do território. 2014. 163 f. Dissertação. (Mestrado do em Gerenciamento Costeiro). Instituto de Oceanografia, Universidade Federal do Rio Grande. Rio Grande. 2014.

MACGARIGAL, K., MARKS, B. J. FRAGSTATS: Spatial pattern analysis program for quantifying landscape structure. Portland. USDA Forest Service, 1994. 122 p.

METZGER, J. P. Estrutura da paisagem e fragmentação: análise bibliográfica. Anais da Academia Brasileira de Ciências, São Paulo, v. 71, n. 3, 445-463, 1999.

METZGER, J. P., MULLER, E. Characterizing the complexity of landscape boundaries by remote sensing. Landscape Ecology, Boston, v. 11, n. 2, 65-77, 1996.

ONU - Organização das Nações Unidas. Perspectivas da população mundial. Disponível em: <https://population.un.org/wup/>. Acesso em: 17 de Janeiro de 2019.

REMPEL, R. S., ELKIE, P. C., CARR, A. Patch analyst user's manual: a tool for quantifying landscape structure. Thunder Bay. Ontario Ministry of Natural Resources, Boreal Science, Northwest Science \& Technology, 1999. 22 p.

RIO GRANDE MINERAÇÃO SA. Relatório de Impacto Ambiental do Projeto Retiro. Disponível em: <http://rgminer.com.br/wp-content/uploads/2014/09/rgm-2014-07-03BAIXA.pdf>. Acesso em: 29 de setembro de 2018.

RS-BIODIVERSIDADE. Zoneamento Ecológico Econômico do Litoral Médio do Rio Grande do Sul, Disponível em: <http://www.biodiversidade.rs.gov.br/> Acesso em: 17 de janeiro de 2019.

SANTOS, J. R. Análise do processo de especialização produtiva e da crise do sistema de produção de cebola em São José do Norte - RS. SINERGIA, Rio Grande, v. 11, n. 2, 53-65, 2007.

SOARES-FILHO, B. S. Análise de Paisagem: fragmentação e Mudança. Disponível em: <https://csr.ufmg.br/dinamica_utils/download/files/publications/apostila.pdf>. Acesso em 29 de setembro de 2018. 
TAGLIANI, P. R. A. Ecologia da paisagem da Restinga da Lagoa dos Patos: uma contribuição para o manejo e conservação da reserva da biosfera. Rio Grande. FURG Editora, 2011. 184 p.

TURNER, M. G., GARDNER, R. H., O’NEILL, R. V. Landscape ecology Theory and practice: pattern and process. New York. Springer-Verlag New York, 2001. 406 p.

URBAN, D., O’NEILL, R.V. \& SHUGART, H. Landscap ecology: a hierarchical perspective can help scientists understand spatial patterns. BioScience, Uberlândia, v. 37, n. 2, 119-127, 1987.

ZONNEVELD, I.S. The land unit - a fundamental concept in ladscape ecology applications. Landscape Ecology, Boston, v. 3, n. 2, 67-86. 1989. 